\title{
Planned Duration of Study Subject Participation
}

National Cancer Institute

\section{Source}

National Cancer Institute. Planned Duration of Study Subject Participation. NCI

Thesaurus. Code C70707.

Total estimated length of time of subject's participation in a clinical study; from the time of enrollment to the completion of follow-up as documented in the study protocol. 